\title{
Understanding the Mechanism of Action and Clinical Implications of Anti-Obesity Drugs Recently Approved in Korea
}

\author{
Kyoung Kon Kim* \\ Department of Family Medicine, Gil Medical Center, Gachon University College of Medicine, Incheon, Korea
}

The Korean Ministry of Food and Drug Safety has approved three anti-obesity drugs for long-term management in the past decade. In addition, since 2019, bariatric surgery has been financially supported by National Health Insurance Service in Korea. In this review, the mechanisms of action and the clinical implications of the recently approved anti-obesity drugs, lorcaserin, naltrexone/bupropion, and liraglutide are explained. Lorcaserin stimulates proopiomelanocortin (POMC)/cocaine- and amphetamine-regulated transcript (CART) neurons and inhibits neuropeptide Y (NPY)/agouti-related peptide (AgRP) neurons, which results in the activation of melanocortin 3/4 receptors. Naltrexone/bupropion stimulates POMC neurons through bupropion; this stimulation is augmented by blocking the autoinhibitory mechanism of POMC with naltrexone. The hypophagic effect of liraglutide is mediated through the direct activation of POMC/CART neurons and the indirect suppression of NPY/AgRP neurons through $\gamma$-aminobutyric acid-dependent signaling, with adjunctive suppression of the mesolimbic dopamine reward system. In addition to liraglutide, another glucagon-like peptide-1 receptor agonist, semaglutide, is expected to be added to the list of anti-obesity drugs in the near future. In patients with obesity and high cardiovascular risk, lorcaserin was considered neutral and liraglutide was considered favorable, whereas inconclusive results were obtained for naltrexone/bupropion.

Keywords: Lorcaserin; Naltrexone; Bupropion; Liraglutide

Received: February 26, 2019, Revised: March 6, 2019, Accepted: March 7, 2019

*Corresponding Author: Kyoung Kon Kim https://orcid.org/0000-0003-0374-2571

Tel: +82-32-458-2778, Fax: +82-32-460-3354, E-mail: zaduplum@aim.com 


\section{INTRODUCTION}

There are five methods of obesity treatment: diet, exercise, behavior modification, drugs, and surgery. These treatment modalities can be divided into two categories, active and passive, based on the perspective of the patient. The active methods, including diet, exercise, and behavior modification, must be done by the patients themselves, whereas the passive methods of pharmacotherapy and bariatric surgery are performed by medical personnel.

A sufficient reduction in food intake and a radical increase in daily activity can reduce excess body weight and then maintain normal body weight in almost all patients with obesity. However, it is well established, through clinical experience and many previous clinical trials, ${ }^{1)}$ that the standard active treatments are not strong enough to induce clinically significant weight loss. Very few patients with obesity can resist hunger and select low-energy-density foods when facing the excess availability of high-energy-density foods. Moreover, very few patients with obesity can maintain an active daily life given the present social prevalence of sedentary lifestyles. Thus, obesity specialists are constantly seeking passive methods of weight reduction.

Over the past decade, there have been major changes in the global treatment of obesity, and in Korea. Between 1964 and 2009, 25 antiobesity drugs, most of which were monoamine neurotransmitter reuptake inhibitors or releasers, were withdrawn after marketing in several countries or worldwide due to cardiotoxicity or potential for drug abuse/dependency. ${ }^{2)}$ Consequently, in 2009, orlistat was the only antiobesity drug approved for long-term treatment in Korea. However, Korean Ministry of Food and Drug Safety has approved three more antiobesity drugs for long-term management in the past decade and another drug is under consideration for approval. The currently prescribed anti-obesity drugs are listed in Table 1, along with their status in the controlled substances schedule, by the US Drug Enforcement Administration. ${ }^{3)}$ In addition, since 2019, bariatric surgery has been supported financially by the National Health Insurance Service.

In this review paper, the mechanisms of action and the clinical implications of the recently approved anti-obesity drugs, lorcaserin, naltrexone/bupropion, and liraglutide, will be described.

\section{MECHANISM OF ACTION OF CENTRALLY ACTING ANTI-OBESITY DRUGS}

In the previous era of anti-obesity drugs, it was unclear how the centrally acting anti-obesity drugs suppressed appetite; however, the mechanism of action of orlistat, a gastric/pancreatic lipase inhibitor that inhibits the absorption of dietary fat in the small intestine, was well characterized. However, the appetite-suppressing mechanisms of lorcaserin, naltrexone/bupropion, and liraglutide are easy to understand. Before the mechanism of action of anti-obesity drugs is described, a brief overview of the mechanism of energy homeostasis in the brain will be provided.

\section{Energy Homeostasis and the Arcuate Nucleus}

For the maintenance of energy homeostasis, it is essential to sense the peripheral signals related to the amount and accessibility of energy. The signals can be divided into two groups: the relatively stable signals that describe the amount of overall stored energy in the body; and the rapidly changing signals that describe the sudden energy consumption, the recent food intake, food availability, and anticipated energy consumption. These peripheral signals of body energy status are considered to be transferred to a specific region of the brain through the humoral and neural pathways and are integrated there. The signaling routes for the control of obesity have been described in detail previously. ${ }^{4)}$

The neurons in the arcuate nucleus of the hypothalamus, which control food intake and energy expenditure, can be grouped into two major populations: orexigenic neurons, which express neuropeptide $Y$ (NPY) and/or agouti-related peptide (AgRP); and anorexigenic neurons, which express proopiomelanocortin (POMC) and/or cocaineand amphetamine-regulated transcript (CART). These two neuron populations gather and integrate the peripheral signals related to the current energy status of body, the presence of food, and the amount of food intake, and they activate the feeding center or transmit signs of satiety, which stop feeding behavior and suppress feeding actions for a certain period of time. Downstream of the POMC/CART neurons, the activation of melanocortin (MC) 3 and 4 receptors by $\alpha$-melanocyte

Table 1. Commonly used drugs for weight reduction

\begin{tabular}{lll}
\hline \multicolumn{1}{c}{ Drug } & Approval status in MFDS & Drug category \\
\hline Phentermine & Short-term & Sympathomimetic amine \\
Phendimetrazine & Short-term & Sympathomimetic amine \\
Diethylpropion & Short-term & Sympathomimetic amine \\
Mazindol & Short-term & Sympathomimetic amine \\
Orlistat & Long-term & Gastric/pancreatic lipase inhibitor \\
Lorcaserin & Long-term & 5-HT2C receptor agonist \\
Naltrexone/Bupropion & Long-term & Opioid antagonist/anti-depressant \\
Liraglutide & Long-term & GLP-1 analogue \\
Phentermine/Topiramate & Under consideration & Sympathomimetic amine/antiepileptic drug
\end{tabular}

Controlled substance schedules are divided into five classes according to the medical usage and the relative abuse potential of each substance by the US Drug Enforcement Administration. For the definition of schedules and example drugs, refer to reference number $3{ }^{3)}$

MFDS, Korean Ministry of Food and Drug Safety; NA, not applicable; GLP-1, glucagon-like peptide 1. 
stimulating hormone occurs (Figure 1).

\section{Serotonergic Satiety in Brain}

Serotonin (5-hydroxytryptophan, 5-HT) is a monoamine neurotransmitter that is been well conserved across species throughout evolution. ${ }^{5)}$ The 5-HT system and receptors are quite varied and the 5-HT receptors have been grouped into seven families, $5-\mathrm{HT}_{1}$ to $5-\mathrm{HT}_{7}$, which include 14 known subtypes. ${ }^{5)} 5$-HT is involved in diverse physiology, including cognition, mood, sexual behavior, and feeding behavior. ${ }^{5)}$

Although 5-HT has been conserved well throughout evolution, 5 -HT systems are different in invertebrate animals and mammals. Although 5-HT neurons are broadly distributed throughout the CNS in lophotrochozoan invertebrates, they are concentrated largely in the raphe nucleus in mammals. ${ }^{6}$ The role of 5-HT in eating behavior is not the same in invertebrates and mammals. In invertebrate animals, 5 -HT promotes feeding behavior, whereas in mammals, its main role is in the induction of satiety. ${ }^{6}$

For the investigation of the involvement of 5-HT receptor subtypes in satiety, several compounds that differ in their affinity to the receptor subtypes have been used, including $\mathrm{m}$-chlorophenylpiperazine
(mCPP), RU-24969, 1-(3-trifluoromethylphenyl) piperazine (TFMPP), and 2,5-dimethoxy-4-iodoamphetamine (DOI). ${ }^{7)}$ According to the reports investigating mCPP, RU-24969, TFMPP, and DOI, of the various 5-HT receptors, 5- $\mathrm{HT}_{1 \mathrm{~B}}$ and $5-\mathrm{HT}_{2 \mathrm{C}}$ are predominantly involved in satiety. ${ }^{7)}$

\section{Interaction of Serotonin Satiety System with POMC/CART Neurons and NPYIAgRP Neurons}

The anorexic effects of the serotonin receptor agonist (RA), fenfluramine, which was widely administered to patients with obesity in the early 1990s, were known to be mediated through the central melanocortin system. ${ }^{8)}$ Lam et al. ${ }^{9)}$ reported that $5-\mathrm{HT}_{2 \mathrm{C}}$ receptors were expressed on POMC neurons, and prolonged infusion with BVT.X, a selective $5-\mathrm{HT}_{2 \mathrm{C}} \mathrm{RA}$, significantly increased the expression of POMC mRNA, which was not observed in MC4 receptor knockout mice. The MC3 receptor was reported to be more likely downstream of serotonin-induced hypophagia, through a study of MC3 knockout, MC4 knockout, and MC3/MC4 double knockout mice. ${ }^{10)}$ Moreover, the systemic administration of fenfluramine can acutely suppress the expression of NPY in hypothalamic neurons, although the expression returns to normal with chronic administration. ${ }^{11,12)} 5-\mathrm{HT}_{1 \mathrm{~B}}$ RAs were shown to

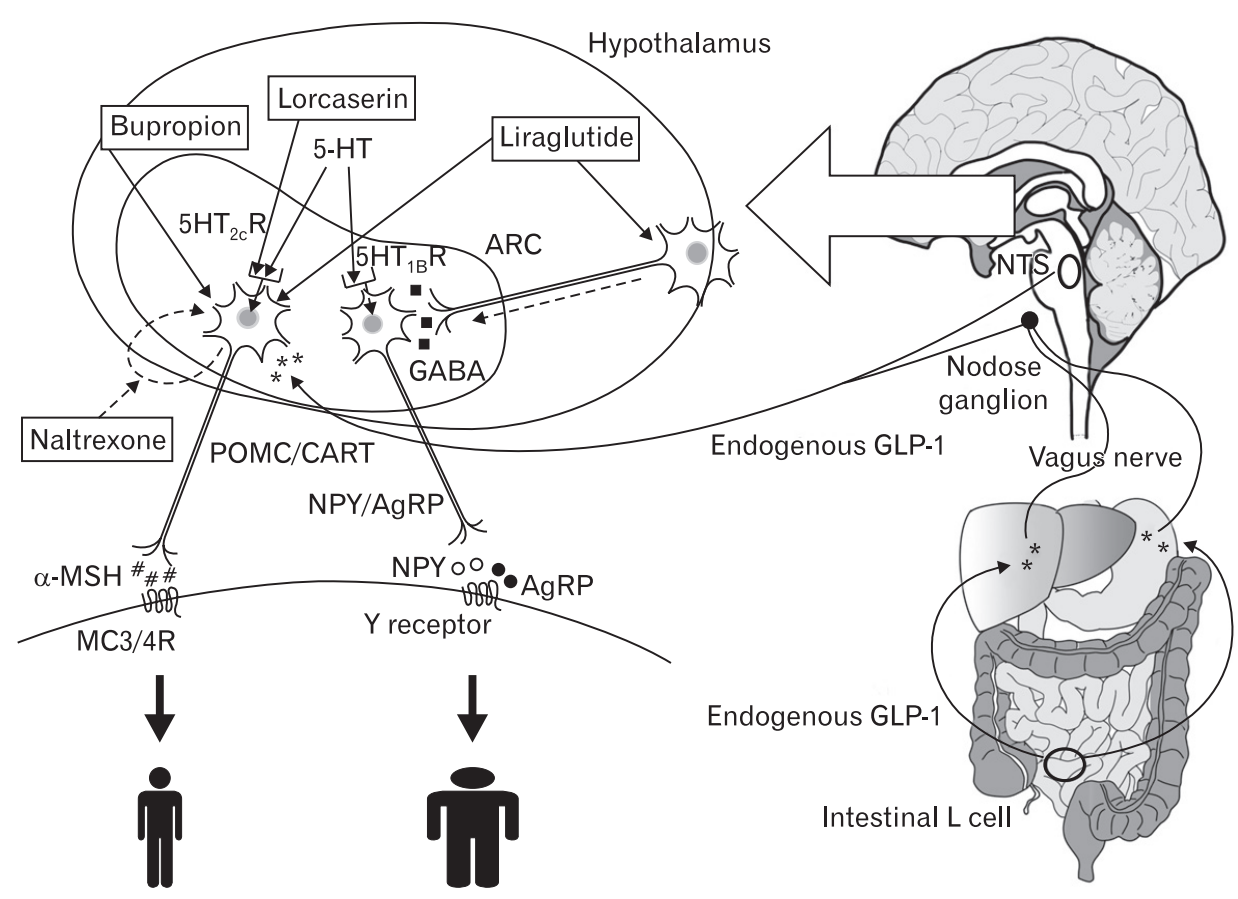

Figure 1. Schematic drawing of appetite control and the mechanisms of action of lorcaserin, naltrexone/bupropion, and liraglutide. Solid arrows mean stimulation and dotted lines mean inhibition. Among the various diverse 5- $\mathrm{HT}$ receptors, $5-\mathrm{HT}_{1 \mathrm{~B}}$ and $5-\mathrm{HT}_{2 \mathrm{C}}$ are mainly involved in satiety. In the serotonin satiety system, 5- $\mathrm{HT}$ suppresses $\mathrm{NPY}(\mathrm{O}) /$ $\mathrm{AgRP}\left(-\right.$ neurons through $5-\mathrm{HT}_{1 \mathrm{~B}}$, but stimulates POMC/CART neurons through $5-\mathrm{HT}_{2 \mathrm{C}}$ receptors. Lorcaserin stimulates POMC/CART neurons, which results in the activation of MC3/4 receptors. The mechanism of action of naltrexone/bupropion is the stimulation of POMC neurons with bupropion, augmented with blocking of the autoinhibitory mechanism of POMC by naltrexone. Endogenous GLP-1(*) is secreted from intestinal endocrine L-cells, which are located mainly in the distal ileum and colon, and preproglucagon-expressing neurons in the NTS of the brain stem. Endogenous GLP-1 from L-cells can activate the hepatic vagal nerve and vagal afferent fibers of nodose ganglion neurons. However, the hypophagic effect of liraglutide depends on its direct activation of POMC/CART neurons and the indirect suppression of NPY/AgRP neurons

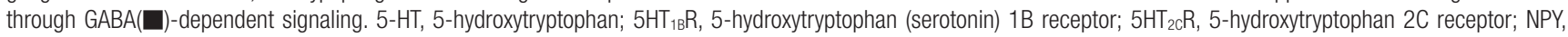
neuropeptide Y; AgRP, agouti-related peptide; POMC, proopiomelanocortin; CART, cocaine- and amphetamine-regulated transcript; MC, melanocortin; GLP-1, glucagon-like peptide-1; NTS, nucleus tractus solitaries; GABA, gamma-aminobutyric acid; ARC, arcuate nucleus; $\alpha$-MSH, $\alpha$-melanocyte stimulating hormone. 
hyperpolarize NPY neurons, whereas $5-\mathrm{HT}_{1 \mathrm{~B}}$ receptor antagonists prevented the hyperpolarization induced by $5-\mathrm{HT}_{1 \mathrm{~B}}$ RAs. ${ }^{13)}$ These findings suggested that 5-HT may directly inhibit NPY/AgRP neuron activity through the inhibitory $5-\mathrm{HT}_{1 \mathrm{~B}}$ receptor.

In conclusion, 5-HT suppresses NPY/AgRP neurons, but stimulates POMC/CART neuron through the $5-\mathrm{HT}_{1 в}$ and $5-\mathrm{HT}_{2 \mathrm{C}}$ receptors, and these effects are transferred to the MC3/4 receptors to induce hypophagia (Figure 1).

\section{Gut to Brain}

Preproglucagon, coded by the proglucagon gene, is processed to glucagon-like peptide-1 (GLP-1), and is secreted from intestinal endocrine L-cells, which are located mainly in the distal ileum and colon, and preproglucagon-expressing neurons in the nucleus tractus solitarius (NTS) of the brain stem. ${ }^{14,15)}$ Although there are many GLP-1 binding sites in the brain, the half-life of endogenous GLP-1 secreted from the gut is too short to reach the brain owing to the rapid degradation; this occurs mainly through dipeptidyl peptidase-4 (DPP-4) and DPP-4 shortens the half-life of GLP-1 to several minutes. However, unlike gutderived endogenous GLP-1, GLP-1 RAs have a much longer half-life owing to their resistance to degradation by DPP-4, conferred by their structural differences, including changes in the amino acid sequence; therefore, some GLP-1 RAs may reach the brain through the humoral pathway, cross the blood-brain barrier (BBB), and attach to GLP-1 binding sites in the brain. GLP-1 RAs that reach the inside of brain may act like brain-derived endogenous GLP-1.

GLP-1 can activate the hepatic vagal nerve and the vagal afferent fibers of nodose ganglion neurons. ${ }^{16,17)}$ In rats with subdiaphragmatic vagal deafferentation, the hypophagic effect of intraperitoneally injected GLP-1 was suppressed in the early stage (until 1 hour) of low-dose administration, whereas the hypophagic effect was observed in the later stages ( $\geq 2$ hours) or by a high-dose administration. ${ }^{18)}$ Similarly, the hypophagic effect of liraglutide was sustained in rats with subdiaphragmatic vagal deafferentation. ${ }^{19)}$ According to these findings, putatively, the neural pathway through the vagus nerve is responsible for a large part of the influence of endogenous gut-derived GLP-1 on the brain, whereas peripherally administered long-acting GLP-1 RAs act directly on brain GLP-1 RAs through the humoral pathway.

\section{Mechanisms of Action of Lorcaserin and Liraglutide}

Considering the energy homeostasis mechanism described above, the action mechanism of lorcaserin, a selective $5-\mathrm{HT}_{2 \mathrm{C}} \mathrm{RA}$, is very clear: it stimulates POMC/CART neurons, which results in the activation of $\mathrm{MC} 3 / 4$ receptors.

However, the weight-reducing mechanism of liraglutide requires further explanation. A well-known effect of gut-derived endogenous GLP-1 is the inhibition of gastric emptying, which is related to the main side effect of liraglutide, nausea. However, the weight loss effect of liraglutide does not appear to depend on the delay in gastric emptying, at least in rats. The chronic administration of the long-acting GLP-

Table 2. Randomized controlled trials of lorcaserin and naltrexone/bupropion for weight reduction

\begin{tabular}{|c|c|c|c|c|c|c|c|c|}
\hline Author (year) & $\begin{array}{c}\text { Study } \\
\text { duration } \\
\text { (wk) }\end{array}$ & Group & No. & Completion & Age (y) & $\begin{array}{l}\text { Initial bodyweight } \\
\qquad(\mathrm{kg})\end{array}$ & $\begin{array}{l}\text { Initial body mass } \\
\text { index }\left(\mathrm{kg} / \mathrm{m}^{2}\right)\end{array}$ & $\begin{array}{l}\text { Mean weight } \\
\text { loss (\%) }\end{array}$ \\
\hline \multirow[t]{2}{*}{ Smith et al. ${ }^{25)}(2010)$} & \multirow[t]{2}{*}{52} & Lorcaserin $20 \mathrm{mg}$ & 1,595 & 883 & 43.8 & $100.4 \pm 0.4$ & $36.2 \pm 0.1$ & -5.8 \\
\hline & & Placebo & 1,587 & 716 & 44.4 & $99.7 \pm 0.4$ & $36.2 \pm 0.1$ & -2.2 \\
\hline \multirow[t]{3}{*}{ Fidler et al. ${ }^{26)}(2011)$} & \multirow[t]{3}{*}{52} & Lorcaserin 20 mg & 1,602 & 917 & 43.8 & $100.1 \pm 15.6$ & $36.0 \pm 4.3$ & -5.8 \\
\hline & & Lorcaserin $10 \mathrm{mg}$ & 801 & 473 & 43.8 & $99.8 \pm 16.6$ & $35.8 \pm 4.3$ & -4.7 \\
\hline & & Placebo & 1,601 & 834 & 43.7 & $100.5 \pm 16.2$ & $35.9 \pm 4.1$ & -2.8 \\
\hline \multirow[t]{3}{*}{ O'Neil et al. ${ }^{27)}(2012)^{*}$} & \multirow[t]{3}{*}{52} & Lorcaserin $20 \mathrm{mg}$ & 256 & 169 & 53.2 & $103.7 \pm 17.0$ & $36.1 \pm 4.5$ & -4.5 \\
\hline & & Lorcaserin $10 \mathrm{mg}$ & 95 & 75 & 53.1 & $106.0 \pm 19.4$ & $36.1 \pm 4.8$ & -5.0 \\
\hline & & Placebo & 253 & 157 & 52.0 & $102.6 \pm 18.1$ & $35.9 \pm 4.5$ & -1.5 \\
\hline \multirow[t]{3}{*}{ Greenway et al..$^{41)}(2010)$} & \multirow[t]{3}{*}{56} & $\begin{array}{l}\text { Naltrexone } 32 \mathrm{mg}+ \\
\text { Bupropion } 360 \mathrm{mg}\end{array}$ & 583 & 296 & 44.4 & $99.7 \pm 15.9$ & $36.1 \pm 4.4$ & -6.1 \\
\hline & & $\begin{array}{l}\text { Naltrexone } 16 \mathrm{mg}+ \\
\text { Bupropion } 360 \mathrm{mg}\end{array}$ & 578 & 284 & 44.4 & $99.5 \pm 14.8$ & $36.2 \pm 4.3$ & -5.0 \\
\hline & & Placebo & 581 & 290 & 43.7 & $99.5 \pm 14.3$ & $36.2 \pm 4.0$ & -1.3 \\
\hline \multirow[t]{2}{*}{ Wadden et al. ${ }^{42)}(2011)^{\dagger}$} & \multirow[t]{2}{*}{56} & $\begin{array}{l}\text { Naltrexone } 32 \mathrm{mg}+ \\
\text { Bupropion } 360 \mathrm{mg}\end{array}$ & 591 & 342 & 45.9 & $100.2 \pm 15.4$ & $36.3 \pm 4.2$ & -9.3 \\
\hline & & Placebo & 202 & 118 & 45.6 & $101.9 \pm 15.0$ & $37.0 \pm 4.2$ & -5.1 \\
\hline \multirow[t]{2}{*}{ Apovian et al. ${ }^{43)}(2013)$} & \multirow[t]{2}{*}{56} & $\begin{array}{l}\text { Naltrexone } 32 \mathrm{mg}+ \\
\text { Bupropion } 360 \mathrm{mg}\end{array}$ & 1,001 & 538 & 44.3 & $100.3 \pm 16.6$ & $36.2 \pm 4.5$ & -6.4 \\
\hline & & Placebo & 495 & 267 & 44.4 & $99.2 \pm 15.9$ & $36.1 \pm 4.3$ & -1.2 \\
\hline \multirow[t]{2}{*}{ Hollander et al. ${ }^{44)}(2013)^{\star}$} & \multirow[t]{2}{*}{56} & $\begin{array}{l}\text { Naltrexone } 32 \mathrm{mg}+ \\
\text { Bupropion } 360 \mathrm{mg}\end{array}$ & 335 & 175 & 54.0 & $104.2 \pm 18.9$ & $36.4 \pm 4.8$ & -5.0 \\
\hline & & Placebo & 170 & 100 & 53.5 & $105.1 \pm 17.0$ & $36.4 \pm 4.5$ & -1.8 \\
\hline
\end{tabular}

Values are presented as number or mean \pm standard deviation. The mean weight loss was calculated for the full analysis set, which comprised all randomized individuals exposed to trial drug with at least one post-randomization weight assessment.

*The participants were patients with obesity and diabetes. Treatment was combined with behavior modification. 
1 RA liraglutide induces desensitization of gastric inhibition, whereas the short-acting GLP-1 RA exenatide does not. ${ }^{20)}$ This is the reason for stepwise up-titration in the administration of liraglutide to the patients.

The hypophagic effect of liraglutide does not rely on the neural pathway through the vagus nerve, and it is independent of GLP-1 receptors in the area postrema and the paraventricular nucleus. ${ }^{19)}$ Liraglutide does not activate endogenous GLP-1-producing neurons in the NTS. ${ }^{19)}$ However, liraglutide acts directly on POMC/CART neurons and NPY/AgRP neurons. Liraglutide increases the expression of POMC mRNA, but does not affect the expression of CART mRNA. ${ }^{19)}$ In the comparison of weight-matched rats, liraglutide-treated rats showed lower expression of NPY mRNA and AgRP mRNA, indicating that liraglutide suppressed the elevation of food-deprived hunger signals. ${ }^{19)}$ However, there are no GLP-1 receptors on NPY/AgRP neurons, and the inhibitory signal of liraglutide on orexigenic NPY neurons is transmitted via $\gamma$-aminobutyric acid (GABA)-dependent signaling. ${ }^{19)}$ In addition, the activation of GLP-1 receptors suppressed the reward system activity of mesolimbic dopamine neurons to highly palatable food intake, which may be a mechanism through which liraglutide demonstrates its hypophagic effect. ${ }^{21)}$

GLP-1 can induce direct thermogenesis. It was demonstrated that GLP-1 increased thermogenesis in rats, mediated by the lower brainstem and the sympathoadrenal system, with a larger increase observed from intravenous administration than from intracerebroventricular administration. ${ }^{22)}$ The thermogenic effect of GLP-1 is induced by the increase in interscapular brown adipose tissue activity, which depends on adrenergic signaling. ${ }^{23)}$ However, the increase in resting energy expenditure was not significant in patients with type 2 diabetes mellitus (T2DM). ${ }^{24)}$

In conclusion, the hypophagic effect of liraglutide depends on the direct activation of POMC/CART neurons and the indirect suppression of NPY/AgRP neurons through GABA-dependent signaling, and the suppression of mesolimbic dopamine reward system (Figure 1). The weight loss results of clinical trials of lorcaserin and GLP-1 RAs are summarized in Tables 2 and 3, respectively. ${ }^{25-32)}$

\section{Combination of Naltrexone/Bupropion}

The fixed dose drug combination of sustained-release (SR) naltrexone $32 \mathrm{mg}$ and SR bupropion $360 \mathrm{mg}(\mathrm{NB})$ is one of the approved antiobesity drugs for long-term treatment in Korea.

In the arcuate nucleus, dopamine receptor activation suppresses NPY neurons and stimulates POMC neurons, most likely through D2 receptors. ${ }^{33,34)}$ The intraperitoneal co-administration of a selective dopamine reuptake inhibitor with a selective norepinephrine reuptake inhibitor showed additive effects on negative energy balance in mice. ${ }^{35}$ Although bupropion, a norepinephrine-dopamine reuptake inhibitor, is unique among anti-depressants owing to its association with weight loss due to its mechanism of action, the extent of weight reduction from bupropion is minimal in patients with obesity. In a randomized placebo-controlled trial, 24-week administration of SR bupropion 300 and $400 \mathrm{mg} / \mathrm{d}$ were associated with mean weight loss of $5.7 \%$ and $7.7 \%$, respectively, compared with that of $4.0 \%$ in the placebo group. $^{36)}$

Table 3. Randomized controlled trials of liraglutide and semaglutide for weight reduction

\begin{tabular}{|c|c|c|c|c|c|c|c|c|}
\hline Author (year) & $\begin{array}{c}\text { Study } \\
\text { duration (wk) }\end{array}$ & Group & No. & Completion & Age (y) & $\begin{array}{l}\text { Initial body } \\
\text { weight (kg) }\end{array}$ & $\begin{array}{l}\text { Initial BMl } \\
\left(\mathrm{kg} / \mathrm{m}^{2}\right)\end{array}$ & $\begin{array}{c}\text { Mean weight } \\
\text { loss (\%) }\end{array}$ \\
\hline \multirow[t]{2}{*}{ Wadden et al. ${ }^{28)}(2013)^{*}$} & \multirow[t]{2}{*}{56} & Liraglutide $3.0 \mathrm{mg}$ & 212 & 159 & 45.9 & $100.4 \pm 20.8$ & $36.0 \pm 5.9$ & -6.2 \\
\hline & & Placebo & 210 & 146 & 46.5 & $98.7 \pm 21.2$ & $35.2 \pm 5.9$ & 0.2 \\
\hline \multirow[t]{2}{*}{ Pi-Sunyer et al..29) (2015) } & \multirow[t]{2}{*}{56} & Liraglutide $3.0 \mathrm{mg}$ & 2,487 & 1,789 & 45.2 & $106.2 \pm 21.2$ & $38.3 \pm 6.4$ & -8.0 \\
\hline & & Placebo & 1,244 & 801 & 45 & $106.2 \pm 21.7$ & $38.3 \pm 6.3$ & -2.6 \\
\hline \multirow[t]{3}{*}{ Davies et al. ${ }^{30)}(2015)^{\dagger}$} & \multirow[t]{3}{*}{56} & Liraglutide $3.0 \mathrm{mg}$ & 423 & 310 & 55.0 & $105.7 \pm 21.9$ & $37.1 \pm 6.5$ & -6.0 \\
\hline & & Liraglutide $1.8 \mathrm{mg}$ & 211 & 154 & 54.9 & $105.7 \pm 21.9$ & $37.0 \pm 6.9$ & -4.7 \\
\hline & & Placebo & 212 & 135 & 54.7 & $106.5 \pm 21.3$ & $37.4 \pm 7.1$ & -2.0 \\
\hline \multirow[t]{2}{*}{ Blackman et al. ${ }^{311}(2016)$} & \multirow[t]{2}{*}{32} & Liraglutide $3.0 \mathrm{mg}$ & 180 & 134 & 48.6 & $116.5 \pm 23.0$ & $38.9 \pm 6.4$ & -5.7 \\
\hline & & Placebo & 179 & 142 & 48.4 & $118.7 \pm 25.4$ & $39.4 \pm 7.4$ & -1.6 \\
\hline \multirow{9}{*}{ O'Neil et al. ${ }^{32)}$ (2018) } & \multirow[t]{9}{*}{52} & Semaglutide $0.05 \mathrm{mg}$ & 103 & 77 & 47 & $111.3 \pm 23.2$ & $39.1 \pm 6.5$ & -6.3 \\
\hline & & Semaglutide $0.1 \mathrm{mg}$ & 102 & 88 & 45 & $111.3 \pm 21.5$ & $39.6 \pm 7.4$ & -9.1 \\
\hline & & Semaglutide $0.2 \mathrm{mg}$ & 103 & 87 & 44 & $114.5 \pm 24.5$ & $40.1 \pm 6.9$ & -12.5 \\
\hline & & Semaglutide $0.3 \mathrm{mg}$ & 103 & 88 & 47 & $111.5 \pm 23.0$ & $39.6 \pm 7.1$ & -12.1 \\
\hline & & Semaglutide 0.4 mg & 102 & 82 & 48 & $113.2 \pm 26.4$ & $39.9 \pm 8.8$ & -14.0 \\
\hline & & Semaglutide $0.3 \mathrm{mg} F$ & 102 & 75 & 47 & $108.1 \pm 22.1$ & $38.2 \pm 6.5$ & -12.3 \\
\hline & & Semaglutide $0.4 \mathrm{mg} \mathrm{FE}$ & 103 & 91 & 46 & $109.6 \pm 21.3$ & $38.5 \pm 5.9$ & -17.0 \\
\hline & & Liraglutide $3.0 \mathrm{mg}$ & 103 & 86 & 49 & $108.7 \pm 21.9$ & $38.6 \pm 6.6$ & -8.3 \\
\hline & & Placebo & 136 & 103 & 46 & $114.2 \pm 25.4$ & $40.1 \pm 7.2$ & -2.3 \\
\hline
\end{tabular}

Values are presented as number or mean \pm standard deviation. The mean weight loss was calculated for the full analysis set, which comprised all randomized individuals exposed to trial drug with at least one post-randomization weight assessment.

$\mathrm{BMI}$, body mass index; FE, fast (2-weekly) dose escalation.

${ }^{*}$ The participants were patients with obesity who lost $\geq 5 \%$ of their initial body weight during a variable-length (4-12 weeks) low-energy diet run-in period. 'The participants were patients with obesity and diabetes (BMl $\geq 27 \mathrm{~kg} / \mathrm{m}^{2}$ with hemoglobin $\mathrm{A} 1_{\mathrm{c}} 7.9 \%-10.0 \%$ ). 
Naltrexone, an opioid receptor antagonist used in the treatment of opioid or alcohol dependence, resulted in the dose-related suppression of eating and drinking in rats. ${ }^{37)}$ Consequently, naltrexone was administered to patients with obesity in several clinical trials in the 1980s to induce weight loss in humans, but the results were unsuccessful. ${ }^{38,39)}$

Although the weight loss effects of bupropion and naltrexone in humans were not satisfactory, in vivo electrophysiology studies by Greenway et al. ${ }^{40)}$ demonstrated that bupropion stimulated POMC neurons and the combination of bupropion and naltrexone showed greater effects on POMC neurons. Animal studies, preclinical, and clinical trials of NB showed that this combination had a greater weight loss effect compared with previous results for the monotherapy of each drug. ${ }^{40-44)}$ In conclusion, the mechanism of action of NB is the stimulation of POMC neurons with bupropion, with this stimulation augmented by blocking of the autoinhibitory mechanism of POMC by naltrexone (Figure 1). The weight loss results of clinical trials of NB are summarized in Table $2 .^{41-44)}$

\section{GLP-1 RECEPTOR AGONISTS FOR THE TREATMENT OF OBESITY: LIRAGLUTIDE AND SEMAGLUTIDE}

Presently, six GLP-1 RAs are used worldwide for the treatment of T2DM: albiglutide, dulaglutide, exenatide, liraglutide, lixisenatide, and semaglutide. Except for semaglutide, these GLP-1 RAs have been approved in Korea. Although the six GLP-1 RAs share a mechanism of action and their basic characteristics, there are differences among the drugs. The detailed similarities and differences of these drugs are beyond this review and are were described. ${ }^{45)}$ Essentially, the GLP-1 RAs can be categorized by their duration of action for the stimulation of the GLP-1 receptor in circulation: short-acting (exenatide and lixisenatide) and long-acting (albiglutide, dulaglutide, exenatide long-acting release, liraglutide, and semaglutide). The main mechanism of the glucose-lowering effect is somewhat different between the two groups. The short-acting GLP-1 RAs inhibit gastric emptying and mainly lower postprandial glucose levels, whereas the long-acting drugs stimulate postprandial insulin secretion and suppress fasting glucagon secretion, which can affect both fasting and postprandial blood glucose levels. . $^{4,46)}$

Endogenous GLP-1, liraglutide, and lixisenatide can cross the BBB and reach the hypothalamus. ${ }^{19,47,48)}$ However, there is no evidence that other GLP-1 RAs cross the BBB. The molecular size and structure of albiglutide and dulaglutide are completely different from endogenous GLP-1; therefore, it is difficult for them to cross BBB and act on the hypothalamic neurons through the humoral pathway.

Of the six GLP-1 RAs, only liraglutide and semaglutide were researched for long-term weight management; liraglutide is currently available in Korea. There have been several large phase 2 and 3 clinical trials for these drugs in the treatment of obesity and the participants and mean weight loss results are summarized in Table $3{ }^{28-32)}$ As shown in the clinical trials, the weight reduction effect of liraglutide was modest (mean weight loss from $-5.7 \%$ to $-8.0 \%$ ) and that of semaglutide was strong (-17\% for rapid dose escalation of $0.4 \mathrm{mg})$. Unlike liraglutide, semaglutide can be administered orally. Oral semaglutide in a tablet form is co-formulated with the absorption enhancer sodium $\mathrm{N}$-[8 (2-hydroxybenzoyl) amino] caprylate. In a clinical trial of daily administered oral semaglutide ( 2.5 to $40 \mathrm{mg}$ ) for 26 weeks in patients with $\mathrm{T} 2 \mathrm{DM}$, the dose-dependent range in the reduction of hemoglobin Alc induced was $-0.7 \%$ to $-1.9 \%$, whereas those induced by $1 \mathrm{mg}$ weekly administered semaglutide through the subcutaneous route and oral placebo were $-1.9 \%$ and $-0.3 \%$, respectively. ${ }^{49)}$ In that trial, the weight reduction in oral semaglutide for each dosage was as follows: placebo, -1.2 kg; $2.5 \mathrm{mg}$ group, - $0.9 \mathrm{~kg} ; 5 \mathrm{mg}$ group, -1.5 kg; $10 \mathrm{mg}$ group, -3.6 kg; $20 \mathrm{mg}$ group, $-5.0 \mathrm{~kg}$; $40 \mathrm{mg}$ standard escalation group, $-5.7 \mathrm{~kg}$. Thus, subcutaneous injection is better than per oral administration for semaglutide. The mainstream obesity treatment of GLP-1 RAs will move to semaglutide from liraglutide in the near future, considering the results of clinical trials. Putatively, in some areas, bariatric surgery can be replaced with semaglutide.

Beyond obesity treatment, liraglutide has some other potential clinical uses. Patients with schizophrenia have high mortality rate; one of the primary causes of their death is cardiovascular disease.$^{50)}$ Although anti-psychotic drugs are effective for the treatment of schizophrenia, they induce weight gain and adverse metabolic effects in patients with schizophrenia. ${ }^{51)}$ In a small clinical trial, liraglutide improved glucose tolerance and reduced body weight in patients with schizophrenia spectrum disorders on clozapine or olanzapine. ${ }^{52)}$

Bariatric surgery induces a large weight reduction in patients with morbid obesity and substantial remission of T2DM. However, T2DM relapses occurred in a considerable number of the patients with diabetes who achieve remission through surgery. ${ }^{53)}$ Small-scale retrospective reports suggested that liraglutide could be an option for patients who experienced poor weight loss or weight regain after bariatric surgery. ${ }^{54,55)}$

Although liraglutide was not approved for patients under 18 years of age in Korea, a randomized controlled 5 week trial of 21 adolescents between 12 and 17 years of age reported that the administration of liraglutide resulted in similar safety and tolerability as administration to adults. $^{56)}$

\section{CARDIOVASCULAR SAFETY OF ANTI-OBESITY DRUGS}

Diabetes is diagnosed from an elevated blood glucose level and nonenzymatic glycation products; thus, the tight control of blood glucose should be the core of the prevention of cardiovascular disease, which is the most common cause of mortality, disability, and financial burden. However, intensive glycemic control was shown to fail in the reduction of macrovascular episodes, even though it reduced microvascular events in well-known large clinical observational or interventional studies. ${ }^{57)}$

It is certain that obesity increases cardiovascular risk and that weight reduction can ameliorate risk. However, similar to the glycemic control 
achieved with anti-diabetic drugs, there is little evidence on whether the weight reduction induced by anti-obesity drugs can decrease or postpone cardiovascular events in patients with obesity. Conversely, several anti-obesity drugs, including fenfluramine and sibutramine, were banned from market owing to their deleterious effects on the cardiovascular system. ${ }^{2)}$ Based on these historical events, newly developed anti-obesity drugs should have proven safety and/or efficacy on cardiovascular events in addition to its weight loss effect.

In the past several years, three clinical trials of the cardiovascular safety of anti-obesity drugs have been performed: the CAMELLIATIMI $61^{58)}$ trial of lorcaserin, the study by Nissen et al. ${ }^{59)}$ of NB, and the LEADER trial of liraglutide in patients with T2DM. ${ }^{60)}$ The results of the trials are summarized in Table 4. In the lorcaserin group, there was no increase in the risk of cardiovascular events during the trial. The liraglutide group (administered up to $1.8 \mathrm{mg}$ daily for the treatment of diabetes) had lower rates of cardiovascular events and all-cause death than the placebo group, although there were no significant differences between the liraglutide and placebo groups with respect to myocardial infarction and for stroke. However, the safety of NB for cardiovascular events was not confirmed, because trial was terminated prematurely owing to early data release. In addition, the cardiovascular safety or efficacy of the higher dosage of liraglutide $(3.0 \mathrm{mg}$ ) for the treatment of obesity has not yet been studied.

Of these three trials, the major cardiovascular events and all-cause death rates were clearly higher in the liraglutide trial (LEADER); this may have been because the proportion of patients with diabetes, the proportion of established cardiovascular disease, and the level of glycated hemoglobin were higher. The lack of cardiovascular benefits in the clinical trials of anti-obesity drugs may be a result of: (1) insufficient length of the study; (2) the moderate cardiovascular risk of participants; and (3) the usage of anti-hypertensive agents, statins, or antiplatelet agents.

\section{CONCLUSION}

Lorcaserin stimulates POMC/CART neurons and inhibits NPY/AgRP neurons, which results in the activation of the MC3/4 receptors. The mechanism of action of NB is the stimulation of POMC neurons with bupropion, augmented with blocking of the autoinhibitory mechanism of POMC by naltrexone. The hypophagic effect of liraglutide depends on its direct activation of POMC/CART neurons and the indirect suppression of NPY/AgRP neurons through GABA-dependent signaling, with adjunctive suppression of the mesolimbic dopamine reward system. Among GLP-1 RAs, semaglutide is expected to be added to the list of anti-obesity drugs in the near future. In patients with obesity patients with high cardiovascular risk, lorcaserin was neutral and liraglutide (up to $1.8 \mathrm{mg}$ ) was favorable, whereas the results of NB were inconclusive.

Table 4. Time-to-event analysis randomized controlled trials of lorcaserin, naltrexone/bupropion, and liraglutide for cardiovascular safety

\begin{tabular}{|c|c|c|c|c|c|c|}
\hline \multirow{2}{*}{ Variable } & \multicolumn{6}{|c|}{ Author (year) } \\
\hline & \multicolumn{2}{|c|}{ Bohula et al. ${ }^{58)}(2018)^{\star}$} & \multicolumn{2}{|c|}{ Nissen et al. ${ }^{59)}(2016)^{\star}$} & \multicolumn{2}{|c|}{ Marso et al. ${ }^{60)}(2016)^{\dagger}$} \\
\hline Noninferiority margin of HR & \multicolumn{2}{|c|}{1.4} & \multicolumn{2}{|c|}{1.4} & \multicolumn{2}{|c|}{1.3} \\
\hline Follow-up duration & \multicolumn{2}{|c|}{3.3 y $(3.0-3.5 y)$} & \multicolumn{2}{|c|}{$\begin{array}{l}121 \text { wk (114-128 wk) with } \\
\text { 2-week crossover run-in }\end{array}$} & \multicolumn{2}{|c|}{3.8 y with 2-week placebo run-in } \\
\hline Group & Lorcaserin $20 \mathrm{mg}$ & Placebo & NB & Placebo & Liraglutide $1.8 \mathrm{mg}$ & Placebo \\
\hline No. & 6,000 & 6,000 & 4,455 & 4,450 & 4,668 & 4,672 \\
\hline $\begin{array}{l}\text { No. of AEs leading to } \\
\text { discontinuation of study drug }\end{array}$ & $433(7.22)$ & $220(3.67)$ & $1,253(28.1)$ & $388(8.7)$ & $444(9.5)$ & $339(7.3)$ \\
\hline Age (y) & $64(58-69)$ & $64(58-69)$ & $61.1 \pm 7.27$ & $60.9 \pm 7.38$ & $64.2 \pm 7.2$ & $64.4 \pm 7.2$ \\
\hline Initial bodyweight (kg) & $102(90-116)$ & $102(90-116)$ & $105.6 \pm 19.1$ & $106.3 \pm 19.2$ & $91.9 \pm 21.2$ & $91.6 \pm 20.8$ \\
\hline Initial body mass index $\left(\mathrm{kg} / \mathrm{m}^{2}\right)$ & $35(32-39)$ & $35(32-39)$ & $36.6(33.1-40.8)$ & $36.7(33.1-41.1)$ & $32.5 \pm 6.3$ & $32.5 \pm 6.3$ \\
\hline Male & $3,888(64.8)$ & $3,814(63.6)$ & $2,018(55.3)$ & $2,031(55.6)$ & $3,011(64.5)$ & $2,992(64.0)$ \\
\hline \multicolumn{7}{|l|}{ Baseline condition } \\
\hline Diabetes & $3,385(56.4)$ & $3,431(57.2)$ & $3,784(84.9)$ & $3,803(85.5)$ & 4,668 (100.0) & $4,672(100.0)$ \\
\hline Glycated hemoglobin (\%) & $6.1(5.7-7.0)$ & $6.1(5.6-7.0)$ & $7.0(6.1-8.1)^{\ddagger}$ & $7.1(6.4-8.2)^{\ddagger}$ & $8.7 \pm 1.6$ & $8.7 \pm 1.5$ \\
\hline Cardiovascular disease & $4,488(74.8)$ & $4,470(74.5)$ & $1,415(31.8)$ & $1,447(32.5)$ & $3,831(82.1)$ & $3,767(80.6)$ \\
\hline Mean weight loss & $-4.2 \mathrm{~kg}$ at $1 \mathrm{y}$ & $-1.4 \mathrm{~kg}$ at $1 \mathrm{y}$ & $-3.6 \%$ & $-1.1 \%$ & \multicolumn{2}{|c|}{ Difference between group was $2.3 \mathrm{~kg}$} \\
\hline MACE at trial completion & 364 & 369 & 124 & 119 & 608 & 694 \\
\hline MACE at interim analysis & 242 & 241 & 90 & 102 & NA & NA \\
\hline All cause death & 212 & 202 & 43 & 51 & 381 & 447 \\
\hline HR $(95 \%$ Cl) for MACE & $0.99(0.85-1.14)$ & & $0.95(0.65-1.38)^{\S}$ & & $0.87(0.78-0.97)$ & \\
\hline
\end{tabular}

Values are presented as number (\%), median (interquartile range), or mean \pm standard deviation, unless otherwise stated.

HR, hazard ratio; NB, naltrexone 32 mg+bupropion 360 mg; AE, adverse event; MACE, major cardiovascular events (a composite of cardiovascular death, myocardial infarction, and stroke); NA, not applicable; $\mathrm{Cl}$, confidence interval.

${ }^{*}$ The participants were people with obesity and pre-existing cardiovascular disease or with an increased cardiovascular risk. ${ }^{\dagger}$ The participants were patients with type 2 diabetes and high cardiovascular risk. ${ }^{\ddagger}$ Glycated hemoglobin level in patients with diabetes, median (interquartile range). ${ }^{8} 99.7 \% \mathrm{Cl}$. 


\section{CONFLICT OF INTEREST}

Kyoung Kon Kim received honorarium from Alvogen, Kwangdong, Ildong, and Novo Nordisk. Kyoung Kon Kim received research funding from Ildong. No potential conflict of interest relevant to this article was reported.

\section{REFERENCES}

1. Miller WC, Koceja DM, Hamilton EJ. A meta-analysis of the past 25 years of weight loss research using diet, exercise or diet plus exercise intervention. Int J Obes Relat Metab Disord 1997;21:941-7.

2. Onakpoya IJ, Heneghan CJ, Aronson JK. Post-marketing withdrawal of anti-obesity medicinal products because of adverse drug reactions: a systematic review. BMC Med 2016;14:191.

3. Diversion Control Division. Controlled substance schedules [Internet]. Springfield (VA): Diversion Control Division, Drug Enforcement Administration, U.S. Department of Justice [cited 2019 Feb 18]. Available from: https://www.deadiversion.usdoj.gov/schedules/index.html.

4. Badman MK, Flier JS. The gut and energy balance: visceral allies in the obesity wars. Science 2005;307:1909-14.

5. Beliveau V, Ganz M, Feng L, Ozenne B, Hojgaard L, Fisher PM, et al. A high-resolution in vivo atlas of the human brain's serotonin system. J Neurosci 2017;37:120-8.

6. Gillette R. Evolution and function in serotonergic systems. Integr Comp Biol 2006;46:838-46.

7. Voigt JP, Fink H. Serotonin controlling feeding and satiety. Behav Brain Res 2015;277:14-31.

8. Heisler LK, Cowley MA, Tecott LH, Fan W, Low MJ, Smart JL, et al. Activation of central melanocortin pathways by fenfluramine. Science 2002;297:609-11.

9. Lam DD, Przydzial MJ, Ridley SH, Yeo GS, Rochford JJ, O’Rahilly S, et al. Serotonin 5-HT2C receptor agonist promotes hypophagia via downstream activation of melanocortin 4 receptors. Endocrinology 2008;149:1323-8.

10. Rowland NE, Fakhar KJ, Robertson KL, Haskell-Luevano C. Effect of serotonergic anorectics on food intake and induction of Fos in brain of mice with disruption of melanocortin 3 and/or 4 receptors. Pharmacol Biochem Behav 2010;97:107-11.

11. Rogers P, McKibbin PE, Williams G. Acute fenfluramine administration reduces neuropeptide $\mathrm{Y}$ concentrations in specific hypothalamic regions of the rat: possible implications for the anorectic effect of fenfluramine. Peptides 1991;12:251-5.

12. Choi S, Blake V, Cole S, Fernstrom JD. Effects of chronic fenfluramine administration on hypothalamic neuropeptide mRNA expression. Brain Res 2006;1087:83-6.

13. Heisler LK, Jobst EE, Sutton GM, Zhou L, Borok E, Thornton-Jones Z, et al. Serotonin reciprocally regulates melanocortin neurons to modulate food intake. Neuron 2006;51:239-49.

14. Baggio LL, Drucker DJ. Biology of incretins: GLP-1 and GIP. Gastroenterology 2007;132:2131-57.

15. Larsen PJ, Tang-Christensen M, Holst JJ, Orskov C. Distribution of glucagon-like peptide- 1 and other preproglucagon-derived peptides in the rat hypothalamus and brainstem. Neuroscience 1997;77:257-70.
16. Nishizawa M, Nakabayashi H, Uchida K, Nakagawa A, Niijima A. The hepatic vagal nerve is receptive to incretin hormone glucagon-like peptide-1, but not to glucose-dependent insulinotropic polypeptide, in the portal vein. J Auton Nerv Syst 1996;61:149-54.

17. Kakei M, Yada T, Nakagawa A, Nakabayashi H. Glucagon-like peptide- 1 evokes action potentials and increases cytosolic Ca2+ in rat nodose ganglion neurons. Auton Neurosci 2002;102:39-44.

18. Labouesse MA, Stadlbauer U, Weber E, Arnold M, Langhans W, Pacheco-Lopez G. Vagal afferents mediate early satiation and prevent flavour avoidance learning in response to intraperitoneally infused exendin-4. J Neuroendocrinol 2012;24:1505-16.

19. Secher A, Jelsing J, Baquero AF, Hecksher-Sorensen J, Cowley MA, Dalboge LS, et al. The arcuate nucleus mediates GLP-1 receptor agonist liraglutide-dependent weight loss. J Clin Invest 2014;124:4473-88.

20. Jelsing J, Vrang N, Hansen G, Raun K, Tang-Christensen M, Knudsen LB. Liraglutide: short-lived effect on gastric emptying: long lasting effects on body weight. Diabetes Obes Metab 2012;14:531-8.

21. Wang XF, Liu JJ, Xia J, Liu J, Mirabella V, Pang ZP. Endogenous glucagon-like peptide-1 suppresses high-fat food intake by reducing synaptic drive onto mesolimbic dopamine neurons. Cell Rep 2015;12:72633.

22. Osaka T, Endo M, Yamakawa M, Inoue S. Energy expenditure by intravenous administration of glucagon-like peptide-1 mediated by the lower brainstem and sympathoadrenal system. Peptides 2005;26:162331.

23. Lockie SH, Heppner KM, Chaudhary N, Chabenne JR, Morgan DA, Veyrat-Durebex C, et al. Direct control of brown adipose tissue thermogenesis by central nervous system glucagon-like peptide-1 receptor signaling. Diabetes 2012;61:2753-62.

24. Horowitz M, Flint A, Jones KL, Hindsberger C, Rasmussen MF, Kapitza C, et al. Effect of the once-daily human GLP-1 analogue liraglutide on appetite, energy intake, energy expenditure and gastric emptying in type 2 diabetes. Diabetes Res Clin Pract 2012;97:258-66.

25. Smith SR, Weissman NJ, Anderson CM, Sanchez M, Chuang E, Stubbe S, et al. Multicenter, placebo-controlled trial of lorcaserin for weight management. N Engl J Med 2010;363:245-56.

26. Fidler MC, Sanchez M, Raether B, Weissman NJ, Smith SR, Shanahan WR, et al. A one-year randomized trial of lorcaserin for weight loss in obese and overweight adults: the BLOSSOM trial. J Clin Endocrinol Metab 2011;96:3067-77.

27. O'Neil PM, Smith SR, Weissman NJ, Fidler MC, Sanchez M, Zhang J, et al. Randomized placebo-controlled clinical trial of lorcaserin for weight loss in type 2 diabetes mellitus: the BLOOM-DM study. Obesity (Silver Spring) 2012;20:1426-36.

28. Wadden TA, Hollander P, Klein S, Niswender K, Woo V, Hale PM, et al. Weight maintenance and additional weight loss with liraglutide after low-calorie-diet-induced weight loss: the SCALE Maintenance randomized study. Int J Obes 2005 2013;37:1443-51.

29. Pi-Sunyer X, Astrup A, Fujioka K, Greenway F, Halpern A, Krempf M, et al. A randomized, controlled trial of $3.0 \mathrm{mg}$ of liraglutide in weight management. N Engl J Med 2015;373:11-22.

30. Davies MJ, Bergenstal R, Bode B, Kushner RF, Lewin A, Skjoth TV, et al. Efficacy of liraglutide for weight loss among patients with type 2 diabetes: the SCALE Diabetes Randomized Clinical Trial. JAMA 2015;314: 687-99. 
31. Blackman A, Foster GD, Zammit G, Rosenberg R, Aronne L, Wadden T, et al. Effect of liraglutide $3.0 \mathrm{mg}$ in individuals with obesity and moderate or severe obstructive sleep apnea: the SCALE Sleep Apnea randomized clinical trial. Int J Obes (Lond) 2016;40:1310-9.

32. O’Neil PM, Birkenfeld AL, McGowan B, Mosenzon O, Pedersen SD, Wharton S, et al. Efficacy and safety of semaglutide compared with liraglutide and placebo for weight loss in patients with obesity: a randomised, double-blind, placebo and active controlled, dose-ranging, phase 2 trial. Lancet 2018;392:637-49.

33. Pelletier G, Simard J. Dopaminergic regulation of pre-proNPY mRNA levels in the rat arcuate nucleus. Neurosci Lett 1991;127:96-8.

34. Tong Y, Pelletier G. Role of dopamine in the regulation of proopiomelanocortin (POMC) mRNA levels in the arcuate nucleus and pituitary gland of the female rat as studied by in situ hybridization. Brain Res Mol Brain Res 1992;15:27-32.

35. Billes SK, Cowley MA. Inhibition of dopamine and norepinephrine reuptake produces additive effects on energy balance in lean and obese mice. Neuropsychopharmacology 2007;32:822-34.

36. Anderson JW, Greenway FL, Fujioka K, Gadde KM, McKenney J, O'Neil PM. Bupropion SR enhances weight loss: a 48-week doubleblind, placebo- controlled trial. Obes Res 2002;10:633-41.

37. Holtzman SG. Suppression of appetitive behavior in the rat by naloxone: lack of effect of prior morphine dependence. Life Sci 1979;24:21926.

38. Atkinson RL, Berke LK, Drake CR, Bibbs ML, Williams FL, Kaiser DL. Effects of long-term therapy with naltrexone on body weight in obesity. Clin Pharmacol Ther 1985;38:419-22.

39. Spiegel TA, Stunkard AJ, Shrager EE, O'Brien CP, Morrison MF, Stellar E. Effect of naltrexone on food intake, hunger, and satiety in obese men. Physiol Behav 1987;40:135-41.

40. Greenway FL, Whitehouse MJ, Guttadauria M, Anderson JW, Atkinson RL, Fujioka K, et al. Rational design of a combination medication for the treatment of obesity. Obesity (Silver Spring) 2009;17:30-9.

41. Greenway FL, Fujioka K, Plodkowski RA, Mudaliar S, Guttadauria M, Erickson J, et al. Effect of naltrexone plus bupropion on weight loss in overweight and obese adults (COR-I): a multicentre, randomised, double-blind, placebo-controlled, phase 3 trial. Lancet 2010;376:595605 .

42. Wadden TA, Foreyt JP, Foster GD, Hill JO, Klein S, O'Neil PM, et al. Weight loss with naltrexone SR/bupropion SR combination therapy as an adjunct to behavior modification: the COR-BMOD trial. Obesity (Silver Spring) 2011;19:110-20.

43. Apovian CM, Aronne L, Rubino D, Still C, Wyatt H, Burns C, et al. A randomized, phase 3 trial of naltrexone SR/bupropion SR on weight and obesity-related risk factors (COR-II). Obesity (Silver Spring) 2013;21:935-43.

44. Hollander P, Gupta AK, Plodkowski R, Greenway F, Bays H, Burns C, et al. Effects of naltrexone sustained-release/bupropion sustained-release combination therapy on body weight and glycemic parameters in overweight and obese patients with type 2 diabetes. Diabetes Care 2013;36:4022-9.

45. Gentilella R, Pechtner V, Corcos A, Consoli A. Glucagon-like peptide-1 receptor agonists in type 2 diabetes treatment: are they all the same? Diabetes Metab Res Rev 2019;35:e3070

46. Meier JJ. GLP-1 receptor agonists for individualized treatment of type 2 diabetes mellitus. Nat Rev Endocrinol 2012;8:728-42.

47. Kastin AJ, Akerstrom V, Pan W. Interactions of glucagon-like peptide-1 (GLP-1) with the blood-brain barrier. J Mol Neurosci 2002;18:7-14.

48. Hunter K, Holscher C. Drugs developed to treat diabetes, liraglutide and lixisenatide, cross the blood brain barrier and enhance neurogenesis. BMC Neurosci 2012;13:33.

49. Davies M, Pieber TR, Hartoft-Nielsen ML, Hansen OKH, Jabbour S, Rosenstock J. Effect of oral semaglutide compared with placebo and subcutaneous semaglutide on glycemic control in patients with type 2 diabetes: a randomized clinical trial. JAMA 2017;318:1460-70.

50. Hennekens CH, Hennekens AR, Hollar D, Casey DE. Schizophrenia and increased risks of cardiovascular disease. Am Heart J 2005;150:1115-21.

51. Maayan L, Correll CU. Management of antipsychotic-related weight gain. Expert Rev Neurother 2010;10:1175-200.

52. Larsen JR, Vedtofte L, Jakobsen MS, Jespersen HR, Jakobsen MI, Svensson CK, et al. Effect of liraglutide treatment on prediabetes and overweight or obesity in clozapine- or olanzapine-treated patients with schizophrenia spectrum disorder: a randomized clinical trial. JAMA Psychiatry 2017;74:719-28.

53. Ganguly S, Tan HC, Lee PC, Tham KW. Metabolic bariatric surgery and type 2 diabetes mellitus: an endocrinologist's perspective. J Biomed Res 2015;29:105-11.

54. Pajecki D, Halpern A, Cercato C, Mancini M, de Cleva R, Santo MA. Short-term use of liraglutide in the management of patients with weight regain after bariatric surgery. Rev Col Bras Cir 2013;40:191-5.

55. Gorgojo-Martínez JJ, Feo-Ortega G, Serrano-Moreno C. Effectiveness and tolerability of liraglutide in patients with type 2 diabetes mellitus and obesity after bariatric surgery. Surg Obes Relat Dis 2016;12:185663.

56. Danne T, Biester T, Kapitzke K, Jacobsen SH, Jacobsen LV, Petri KC, et al. Liraglutide in an adolescent population with obesity: a randomized, double-blind, placebo-controlled 5-week trial to assess safety, tolerability, and pharmacokinetics of liraglutide in adolescents aged 12-17 years. J Pediatr 2017;181:146-53.

57. Macisaac RJ, Jerums G. Intensive glucose control and cardiovascular outcomes in type 2 diabetes. Heart Lung Circ 2011;20:647-54.

58. Bohula EA, Scirica BM, Inzucchi SE, McGuire DK, Keech AC, Smith SR, et al. Effect of lorcaserin on prevention and remission of type 2 diabetes in overweight and obese patients (CAMELLIA-TIMI 61): a randomised, placebo-controlled trial. Lancet 2018;392:2269-79.

59. Nissen SE, Wolski KE, Prcela L, Wadden T, Buse JB, Bakris G, et al. Effect of naltrexone-bupropion on major adverse cardiovascular events in overweight and obese patients with cardiovascular risk factors: a randomized clinical trial. JAMA 2016;315:990-1004.

60. Marso SP, Daniels GH, Brown-Frandsen K, Kristensen P, Mann JF, Nauck MA, et al. Liraglutide and cardiovascular outcomes in type 2 diabetes. N Engl J Med 2016;375:311-22. 